\title{
Design of Intelligent Walking Stick for the Elderly based on User Experience Research
}

\author{
Xiaojing Yang, Xiangyang Li \\ School of Art and Design, Guangdong Agriculture Industry Business Polytechnic, Guangzhou, Guangdong, 510507, China
}

\begin{abstract}
Purpose: Using the design ideas and research methods of user experience to probe into design art in the field of the elderly products, thus presenting an innovative intelligent walking stick with a better user experience. Methods: Questionnaire surveys, observation, interviews and other methods were employed to research the life style and travel behavior of the elderly people, gain the users' characteristics, recognition mentality, perception features and other valuable information, identify the present home caring conditions and travel features of the elderly group, thereby obtaining insights into the elderly users' real demand, as well as found out the key selling point of the elderly intelligent walking sticks. Conclusion: On the basis of cluster analysis on the characteristics of the typical user group and the survey results, the persona of users was created and scenario analysis was made in the form of story board to define the needs of the target personas and output the design prototype. After that, the design scheme was completed to offer a reference for design of relevant products.
\end{abstract}

\section{Introduction}

Facing an accelerating aging society issue in China, the customer demand for the elderly products presents a fast growing trend. However, nowadays the domestic market for the elderly products is still in its infancy stage. With incomplete market system, the development of silver industry is far from enough to meet market requirements. This kind of immaturity in elderly product sector results in a mismatch with the ever-growing market demand when it comes to product category or product quality. In particular, a number of enterprises have concerns about investing sufficient funds in early $R \& D$ of elderly products. As a result, neither product design nor user experience is gratifying. In an upcoming era of experience economy, it is essential to stress on "the elderly oriented" by designing up-to-date and excellent elderly products.

\section{User Experience and Design of Elderly Intelligent Walking Stick}

The idea of user experience (UX for short) was proposed by Donald Norman as early as the 1990s. It had got widely cognition afterwards. According to Donald A. Norman's theory, design is not all about technologies and functions, it should care for the emotions too. He believed that one good design must reflect the configuration on instinct level, the operation on behavior level as well as the impression and image on rethinking level. ISO9240-210 standard defines the user experience as a kind of users' cognition impression and feedback on the products, systems or services they accept. That is, user experience covers the whole feeling before using a product or system, in the middle of using and after using them, such as effectiveness, efficiency, accessibility, user satisfaction, aesthetic impression and mood. The user experience design focused on the users. Throughout the design process, it helped to understand and perceive the real expectation and purpose of users and thus made the proper evaluation on product objective.

In accordance with the report of the World Health Organization, almost $28-35 \%$ of the elderly at 65 years' old and elder falls down every year, this number rises up to $32-42 \%$ among the people over 70 years of age. Injuries caused by falling down have become the dominant reason for pain, disability, loss of self-caring ability and even premature death. Walking stick is such an important device to assist the elderly in "walking" and "strolling". It has been an indispensable tool for some of them in everyday life, particularly when they move about. Furthermore, the walking stick can effectively prevent their falling down because of their weak muscle power, visual and hearing decline as well as the environmental obstacle influence.

As a subdivided category, the intelligent walking sticks for the elderly are equally emerging sector. The traditional design is partly short of adaptability and creativity so it cannot wholly meet the diversified and latent demands from the elderly users. The elderly intelligent walking sticks which were designed by the method of user experience, by comparison, pivoted on the elderly people. They had melted the research method and assessment style on user experiences into the process of design. In the hope of inventing such effective, user-

*Corresponding author: 57446857@qq.com 
friendly, comfortable and pleasant experiences, our designers made every effort to get an insight and understanding on the real and latent demands of the elderly.

\section{Design Practice of the Elderly Intelligent Walking Sticks Based on User Experience Research}

\subsection{User Survey}

By combination of the survey data from the early questionnaire, follow-up observation and in-depth interview, it took records, analysis and summary on the elderly lifestyle in the purpose of designing an excellent intelligent walking stick. Questionnaire could collect a great deal of data in a short time. It is a kind of efficient and economical way of survey. Observation is an effective and open method on gaining abundant real information. It helps to find out the unknown phenomena and behaviors and thus excavate latent problems. Interviewing method is developed by asking questions and communicating with users to get their experiences and feelings in the process of use.

Taking the elderly group over 60 years of age as research target, it collected the survey data from two hundred questionnaires; then it observed and interviewed some selected typical users from them thus recording and analyzing their home care status, way of life, travel behavior and other aspects.

\subsection{1. $76 \%$ of the elderly stay with their family.}

The people over 70 years of age see universal decrease in independent viability. When living with their families, they will be taken care of much easier. These aged users usually associate with their offspring and neighbors. They live their lives mainly in acquaintance society.

\subsection{2. $83 \%$ of the elderly are used to keeping early hours, so they have got relatively more leisure time.}

Nevertheless, these aged people are not content with their idle days and they try to find something to do. This is always the way they live and they are willing to maintain the status.

\subsubsection{The everyday life of the elderly revolves around their family and small-scale familiar circumstances.}

They have low intention on consumption. In addition, they prefer not to go traveling or shopping far away from home. When shopping, the elderly will carry the trailers $(21 \%)$ or reusable bags $(47 \%)$ with them.

\subsection{4. $68 \%$ of the elderly prefer walking as their way of traveling, followed by mass transit (18\%) and bicycles (12\%).}

The elderly over 70 years of the age and who suffer from chronic disease tend to travel with their companions.

\subsubsection{The elderly users participate limited ways of entertainment.}

They have relatively smaller range of activities where normally is close to their houses. Their favorable pastimes are watching television, taking a walk, chatting, sometimes also doing some simple and low-intensity body exercises.

\subsection{Set up Personas}

Persona method is also known as user profile method. It is mainly used to describe the fundamental information such as users' characteristics, ages, genders, careers, etc., as well as their demands, behavioral feature, preferences and more information. It is a typical approach of description on target users by collecting and researching a certain amount of real user data. Persona is helpful to specify the real demands of users and usage scenarios, thus building the product orientation.

Based upon the frequency and dependence on walking stick, the elderly users could be divided into two groups: mild dependency and severe dependency group. Selected the 65 years old and elder then extracted their survey data. Built the personas in combination of the typical users from the severe dependency group. Clarified their behavior characteristics and life styles; extracted the typical features of target users and then set up personas.

Table 1. Persona creation

\begin{tabular}{|c|c|}
\hline Item & Detailed Description \\
\hline Persona & $\begin{array}{l}\text { Grandpa Huang, } 70 \text { years old, lives with his offspring. He usually keeps early } \\
\text { hours and always keeps himself busy. Grandpa Huang has trouble in walking } \\
\text { so his normal scope is near his home. Meanwhile, his hypertension requests } \\
\text { him to take medicine in a long time. }\end{array}$ \\
\hline Product use frequency & $\begin{array}{l}\text { Years of usage: } 5 \text {; Daily hours of usage: } 7+\text {; Application environment: indoor } \\
\text { activities, outdoor traveling }\end{array}$ \\
\hline Purpose of use & $\begin{array}{l}\text { Grandpa Huang uses his walking stick mostly because he has trouble in } \\
\text { walking. It can prevent him from tumbling. }\end{array}$ \\
\hline
\end{tabular}




\subsection{Scenario Analysis}

Based on analysis of the characteristics and anticipation of typical persona, it set up the everyday life scenario of the persona and drew his story board. By using visual thinking, it vividly elaborated the interactive details between the user and the product, thus reflecting the mutual influence among the product, application scenario and the user behavior. Valuable problems were found in the early stage of data collection. They were useful to extract the demands of target users and to direct the prototype design.

There are relatively many scenarios that the elderly use walking stick. In particular, the aged people and those who have trouble in walking rely heavily on the walking sticks. However, generally speaking, family life and walking nearby are the most essential usage scenarios. Focusing on the persona of 65 years old and elder, along with the features of their everyday life and traveling, it extracted the sore points from both scenarios of family life and traveling nearby to discover the user desires and their latent requirements.

3.3.1. In the scenario of family life, the elderly are susceptible to fall in poor lighting conditions at night; ordinarily they have limited entertainment styles; Due to deterioration of their eyesight, they found it difficult to read the instructions clearly or to understand the complex product.

\subsubsection{When traveling alone, in case of an accidental} fall caused by sickness or other reasons, the elderly are probably too exhausted to call for help; they may forget to bring medicine with them or cannot find it when they need to take medicine outdoors.

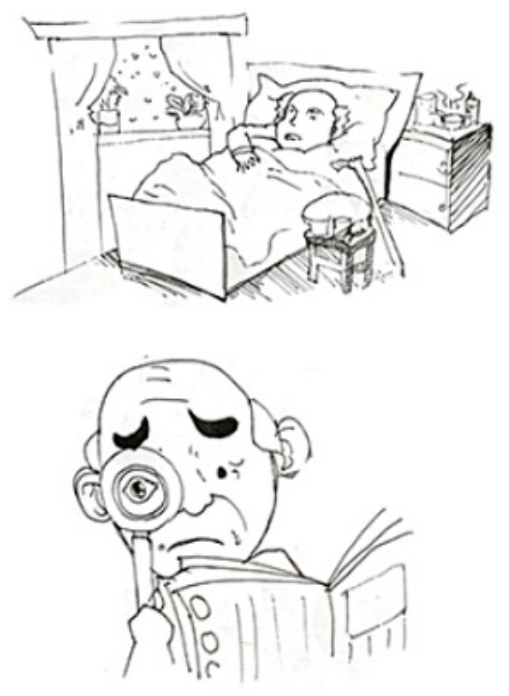

\subsection{Definition of Demands}

The user experience design stresses on subjectivity, especially on the element of "human" among target group. It aimed at efficiently promoting the user experience by their actual experience and use style. The user element plays the most important role in product development. On present market, the traditional walking sticks are so simple in function that they cannot meet the elderly requirements any longer. As emerging walking aids, the intelligent walking sticks are gradually winning the favor the elderly users. In addition to the anti-slippery, auto-scaling, illuminating, alarming and else main functions, so many walking sticks have also added seat, umbrella, telephone call function, heart rate detection and more additional functions. However, brute integration of functions cannot always bring about better using experience. Unexpectedly, the complicated operation method, inconsiderate configuration, weird modeling and else impractical
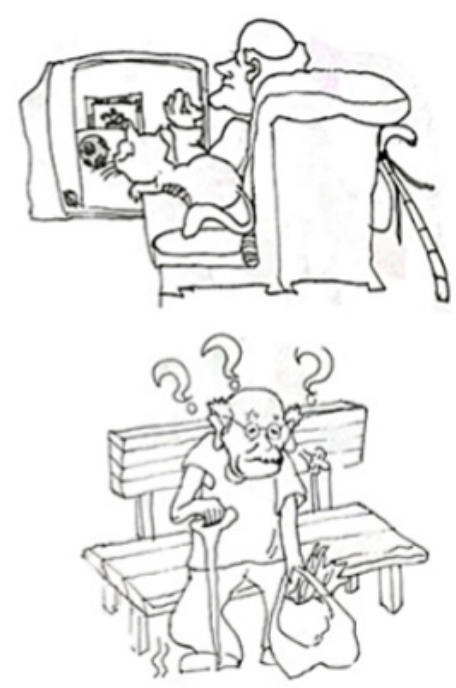

Figure 1. Story Board

functions may plunge the elderly into negative feelings when they use them.

The elderly intelligent walking stick is supposed to be designed as per the elderly users' real demands, rather than the subjective perception of designers. Therefore, insights and comprehension on the target users' real demands are more than important to guarantee the precise orientation of product design. Based on the analysis of typical persona and circumstances, clustered their demands of elderly walking sticks in family lives and outdoor activities. Furthermore, combined with the summarized interview and observation results, classified these demands into four types: interactive demand, functional demand, material demand and modeling demand. 
Table 2. Demand Analysis

\begin{tabular}{|c|c|c|c|}
\hline Interactive Demand & Functional Demand & Material Demand & Appearance Demand \\
\hline $\begin{array}{l}\text { Suitable for various } \\
\text { land conditions; anti- } \\
\text { slippery; } \\
\text { Its size fits the user's } \\
\text { stature. }\end{array}$ & $\begin{array}{l}\text { Multi-functions; } \\
\text { Simple operation; } \\
\text { Adapt for various } \\
\text { application } \\
\text { environments; } \\
\text { preinstall some simple } \\
\text { recreational functions }\end{array}$ & $\begin{array}{c}\text { comfortable material; } \\
\text { light in weight; reliable } \\
\text { and safe }\end{array}$ & Steady; sense of trust \\
\hline
\end{tabular}

\subsection{The Prototype Design of Elderly Walking Stick}

It specified the design requirements via typical user analysis. Took the intelligent walking stick as the design object; analyzed the requirements and designed the prototype on the basis of user characteristics. It began analysis on four requirements: user-friendly interactive relations, useful functions, proper materials and elderly accessibility. Next it determined the design direction of intelligent walking stick, and built the product prototype features: safe, reliable, applicative; the additional functions should adapt environmental and user characteristics. Additionally, the user experience was optimized and the modeling was designed in line with the elderly tastes.

The general design concept focuses on the elderly life style and their traveling requirements. It attempted to integrate the advantages of safety and comfort in traveling, adaptability, solidity and elegancy together.

\subsubsection{The interactive design of the elderly intelligent walking stick followed the principle of adaptability.}

It divided the stick body into upper part and lower part. The length of walking stick was therefore adjustable as per user's stature. The size of stick head was relatively larger so it was convenient for holding. The lower part of the stick head was designed as slip-resistant groove to prevent it slipping out of the hand; the icon design on the operational buttons were easily recognized and remembered.

\subsubsection{The elderly intelligent walking stick applied multi-purpose design.}

As personal belongings, a hidden medical kit was added at the handle of walking stick. This design could greatly reduce the occurrence when the elderly forgot to take necessary medicine. A front light source was added on the stick. When the elderly walk at night with the intelligent stick, they can switch on the low beam or high beam in wake of actual environment thus reducing their accident incidence in dim places; One button for help, in case falling, sickness or any other accidents occurs, the elderly can press the SOS button on the head of walking stick. It then makes beep sound to draw the attention of passersby. In the meantime, the stick automatically sends the location data to their family members through GPS navigation system. Radio function was also added to offer more entertainment.

\subsubsection{The head of the elderly intelligent walking stick adopted plastic material and its body was made of light metal material-aluminum alloy.}

The overall weight is so light that the elderly can save effort when they use it. Moreover, as the major part, the stick body used metal material to provide secure support and its foot pad adopted anti-slippery rubber material to increase friction.

3.5.4. To avoid the risk of prominent edges, the outline of the elderly intelligent walking stick was designed as smooth and rounded.

Its general modeling was simple and steady. It adopted classic black and silver/red colors to create a visual sense of reliability and safety. 

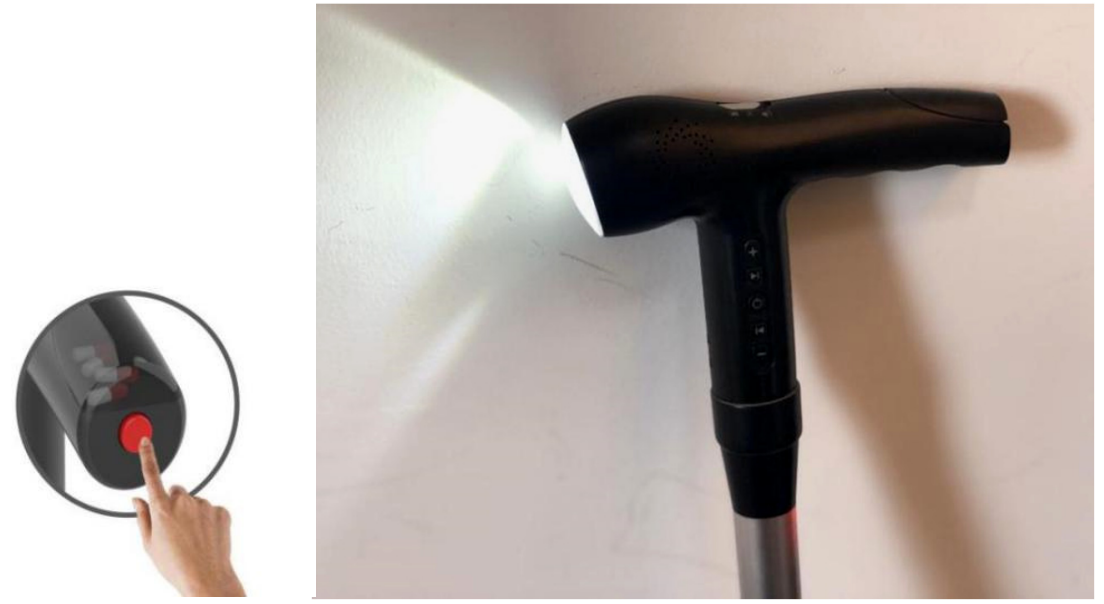

Figure 2. Concept Design \& Physical Prototype

\subsection{Brand Design}

The user experience was reflected throughout the whole process of product use. It comprised not only sensory experience but also behavior experience and emotional experience. The user experience normally involves industrial design, user interface design, package design and more design contents. Therefore, a series of comprehensive and complete work must be carried out to integrate the user experience design into the elderly intelligent walking stick.

\section{又智行 储药式智能拐杖 Intelligent medicine storage crutch}
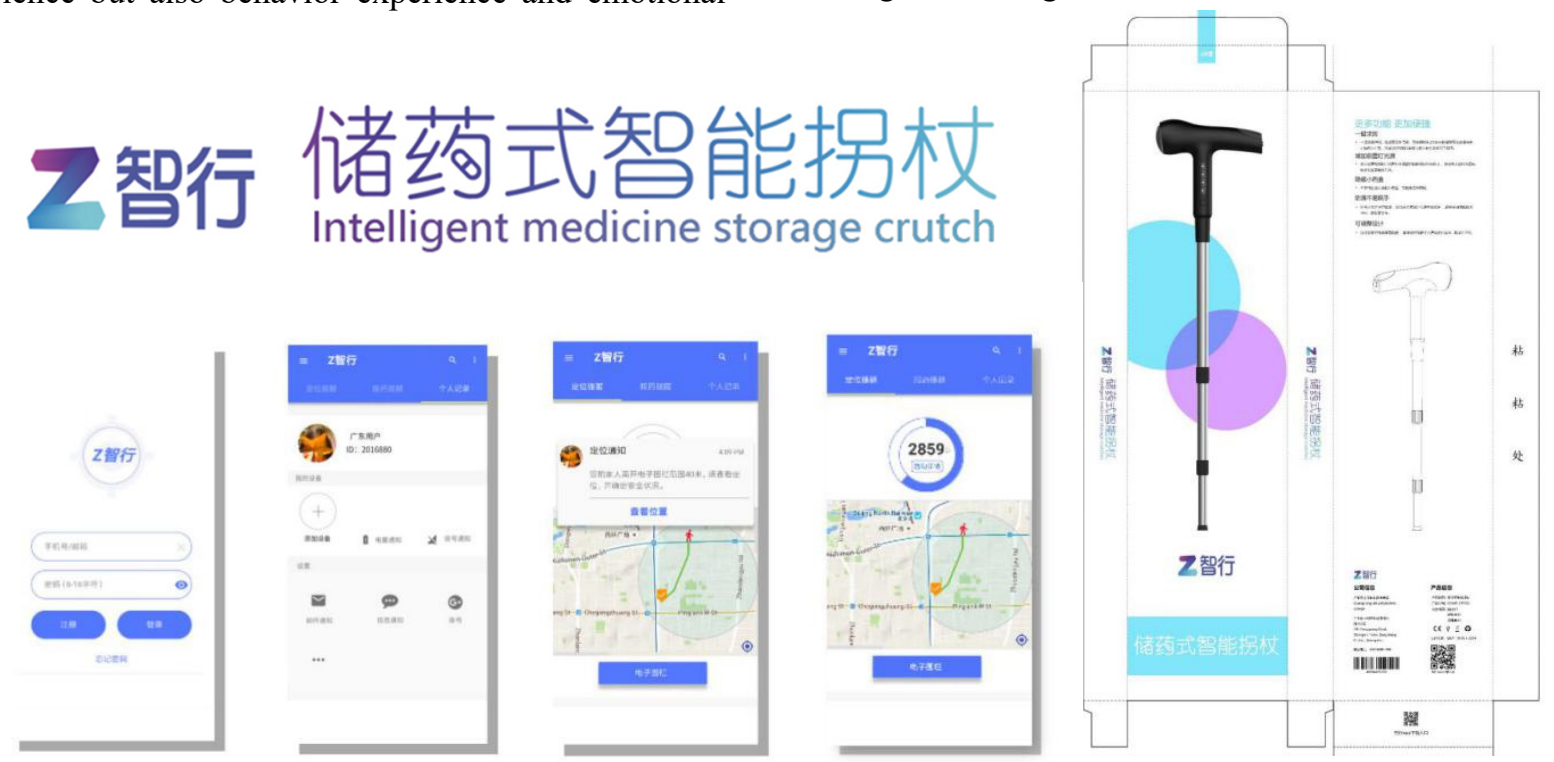

Figure 3. Brand Design

Old-fashioned elements may result in negative visual experience and remind the elderly of their ages. So it's better to use the common but simple elements to create a modern visual experience. The design style of the LOGO and font is simple and friendly,and the instruction in big font size is easy to read. The app UI design considered the demand of the elderly and also their family members. It has practical functions like alarm alert and step counting etc., and the layout is clear.

\section{Conclusion}

The accelerating aging society has raised a new challenge for present market and product design with the development of the elderly sector. User experience has become a hot topic and this trend also takes effect of the elderly products design. It is necessary to ascertain the target group and their actual demands in the process of developing elderly intelligent products. In the meantime, it's equally important to focus on the elderly, then specify and subdivide the design ideas as well as study their physical and psychological features. Only in this way can the simple and functional, safe and reliable products be devised. The purpose of design focuses on the characteristics of aged users. In addition, the design philosophy is all about exploring the elderly intelligent products. These provided solutions and methods for the aging society as well as conveying humanistic care to the elderly by designs. Meanwhile, the design purpose and philosophy offered the elderly considerate and dignified lives together with wonderful life experience. 


\section{Acknowledge}

This paper is supported by Guangzhou 2019 Philosophy and Social Science Program (2019GZGJ157).

\section{References}

1. Donald A. Normand. (2003) The Design of Everyday Things. Zhongxin Press, Beijing.

2. Human-centred Design for Interactive Systems. (2010) ISO DIS 9241-210, Ergonomics of Human System Interaction: Part 210. International Standardization Organization (ISO), Switzerland.

3. World Health Organization. (2007) WHO global report on falls prevention in older age. World Health Organization, Geneva.

4. Fei Hu. (2010) Understand User -User Research Methods and Application. Building Industry Press, Beijing.

5. Hongwei Hu. (2011) Psychological Symptoms and Influencing Factors of the Elderly in China. Journal of Southwest University, 37: 145-152.

6. Mengchen Li, Fenghong Wang, Lin Lin. (2016) Barrier-free Walking Aids Design Aimed at the Elderly of Guangdong Region. Packaging Engineering, 37: 78-79.

7. Jiang Yao, Bing Feng. (2015) Research on Interface Interaction of Older Information Products Based on Design Experience Perspective[J]. Packaging Engineering, 36: 67-69.

8. Ming Zhang. (2014) Innovative Design of Home Health Services for Elderly People. Packaging Engineering, 35: 33-36.

9. Jinhua Dou,Yanling Zheng. (2013) Research on Designing Pleasant Products for the Empty Nest Elderly.Packaging Engineering, 34: 34-37.

10. Jinghao He. (2011) Synaesthesia Design of the Elderly Products in the Digital Era.Packaging Engineering, 32: $30-32$. 